\title{
ATIVIDADE DA PECTINA METILESTERASE E DA $\beta$-GALACTOSIDASE DURANTE O AMADURECIMENTO DO MAMÃO cv. GOLDEN ${ }^{1}$
}

\author{
LUCIANA KONDA DE AZEVEDO PINTO², MEIRE LELIS LEAL MARTINS ${ }^{3}$, \\ EDER DUTRA DE RESENDE ${ }^{4}$, JOSÉ TARCÍSIO LIMA THIÈBAUT
}

RESUMO-Este trabalho foi realizado com o objetivo de investigar o comportamento das enzimas pectina metilesterase (PME) e $\beta$-galactosidase ( $\beta$-Gal) durante o amadurecimento do mamão cv.' Golden '. Mamões com $15 \%$ de cor amarela foram estocados em câmara de refrigeração a $20^{\circ} \mathrm{C}$ e $85-95 \%$ UR, por um período de 11 dias. Durante este período de estocagem, foi determinada a cor da casca, firmeza e pH da polpa dos frutos, bem como a atividade das enzimas PME e $\beta$-Gal. A atividade da PME, observada ao longo do amadurecimento do mamão, indicou que esta enzima participou do processo de hidrólise da parede celular, principalmente no início do amadurecimento dos frutos. Já a atividade da $\beta$-Gal aumentou, de maneira não gradual, do primeiro dia até o final do armazenamento, quando alcançou seu valor máximo. Uma redução drástica na firmeza e no $\mathrm{pH}$ da polpa ocorreu nos três primeiros dias de armazenamento. Neste período, os frutos apresentaram coloração com valores do ângulo hue próximos de 80 , a qual corresponde a uma coloração amarela. Verificou-se que a PME atua de modo efetivo no amadurecimento do mamão, mas a redução precoce em sua atividade indica que a $\beta-$ Gal tem também um papel fundamental na rápida perda de firmeza pelo mamão cv. Golden.

Termos para indexação: Carica papaya, pectina metilesterase, $\beta$-galactosidase, firmeza de polpa.

\section{ACTIVITY OF PECTINMETHYLESTERASE AND $\beta$-GALACTOSIDASE DURING THE RIPENING OF PAPAYA FRUITS cv. GOLDEN}

\begin{abstract}
This study was carried out with the objective to investigate the behavior of the enzymes pectinmethylesterase (PME) and $\beta$-galactosidase ( $\beta$-Gal) during the ripening of the papaya cv. 'Golden'. The fruits with $15 \%$ of yellow peel color were stored in a cold chamber at $20^{\circ} \mathrm{C}$ and $85-95 \% \mathrm{RH}$ for 11 days. During this stored period it was determined the skin color, pulp firmness and $\mathrm{pH}$. The PME activity observed during the papaya storage showed that this enzyme participated in the hydrolyze process of the cell wall mainly at the beginning of the ripening. The $\beta$-Gal activity increased from the $1^{\text {st }}$ day to the end of stored period where reached the maximum activity, although this increase was not gradual. A decrease in the pulp firmness and $\mathrm{pH}$ occurred until the $3^{\text {rd }}$ day of storage. In this same period, the fruits showed peel color with hue angle values around 80 , which corresponds to yellow color. It was verified that the PME acts effectively in the ripening of papaya, however, the decrease in the activity of this enzyme in early periods of storage indicates that the $\beta-$ Gal has an important role in the firmness loss of papaya cv. Golden.
\end{abstract}

Index terms: Carica papaya, pectinmethylesterase; $\beta$-Galactosidase, pulp firmness.

\footnotetext{
${ }^{1}$ (Trabalho 167-10). Recebido em: 19-07-2010. Aceito para publicação em: 15-02-2011.Extraído da Tese de Doutorado em Produção Vegetal da primeira autora.

${ }^{2}$ Doutora em Produção Vegetal, LTA/CCTA/UENF. E-mail: lukonda@yahoo.com

${ }^{3}$ Professora Associada, LTA/CCTA/UENF. E-mail: meire@uenf.br

${ }^{4}$ Professor Associado, LTA/CCTA/UENF. E-mail:eresende@uenf.br

${ }^{5}$ Professor Associado, Laboratório de Engenharia Agrícola, CCTA/UENF. E-mail:jtt1512@uenf.br
} 


\section{INTRODUÇÃO}

O processo de amolecimento é parte integrante do amadurecimento dos frutos e tem grande importância comercial, porque pode limitar a vida pós-colheita e tornar os frutos mais suscetíveis a injúrias mecânicas e a doenças durante o manuseio (BICALHO et al., 2000, JACOMINO et al., 2002).

No mamão, como na maioria dos frutos, o amadurecimento é marcado por modificações texturais, associadas ao metabolismo de carboidratos da parede celular, que culminam com a redução da sua firmeza. As substâncias pécticas constituem a classe de polissacarídeos da estrutura da parede celular que sofrem marcantes modificações durante o amadurecimento dos frutos. Mudanças em pectinas têm sido extensivamente documentadas, como a solubilização e a despolimerização das substâncias pécticas, que normalmente acompanham o amaciamento dos frutos durante o seu amadurecimento (HUBER, 1983, BRUMMELL; LABAVITCH, 1997).

As modificações diferenciadas nos vários componentes da parede celular indicam que existem mecanismos reguladores específicos quanto à concentração e tipo das enzimas (isoformas) e ao tempo de aparecimento de tais estruturas enzimáticas (ASIF; NATH, 2005). Em geral, os componentes da parede celular podem ser modificados durante o amadurecimento, mas o tempo, a velocidade e a extensão dessas modificações catalisadas por enzimas variam acentuadamente entre as diferentes variedades.

A solubilização da pectina, devido ao aumento da atividade da pectina metilesterase (EC 3.1.1.11), parece ser uma das razões para o desenvolvimento do amolecimento, associado com o amadurecimento no mamão (PAULL; CHEN, 1983). A pectina metilesterase promove a desmetilação da pectina através da hidrólise de radicais metila, expondo a carboxila dos ácidos galacturônicos e liberando metanol e pectina de baixa metilação (ARBAISAH et al., 1996). Embora não modifique o comprimento da cadeia de pectina, a pectina metilesterase altera algumas das propriedades do polímero, como, por exemplo, a solubilidade, além de disponibilizar substrato para a ação de outras enzimas, como a poligalacturonase e a $\beta$-Galactosidase.

O padrão de atividade da enzima PME tem sido estudado em diferentes variedades de mamão. Em mamão cv. Eksotika, foi observado um incremento na atividade com o processo de amadurecimento, ocorrendo maior intensidade com a profundidade do mesocarpo (LAZAN et al., 1995). Um aumento de atividade de $600 \%$ para frutos desta mesma va- riedade, entre os estádios pré-climatérico e maduro, foi relatado por Ali et al. (2004). No caso do mamão cv. Sunrise, Paull e Chen (1983) identificaram baixa atividade da PME no período pré-climatérico, que aumentou gradativamente durante o período de armazenamento a $22{ }^{\circ} \mathrm{C}$ e estendeu-se por até 4 dias após o pico de produção do etileno. No caso do mamão cv. Improved Sunrised Solo, Bicalho et al. (2000) observaram aumento na atividade da PME, a partir do estádio pré-climatérico e até 20 dias de armazenamento a $10^{\circ} \mathrm{C}$.

As galactosidases atuam durante o amadurecimento e podem ser rotas alternativas durante esse processo (SOZZI et al., 1996). A $\beta$-Galactosidase (EC 3.2.1.23) é uma enzima hidrolítica que age em conjunto com as enzimas pectolíticas (poligalacturonase e PME) e pode contribuir para o amaciamento de frutos. Sua ação consiste na hidrólise dos resíduos terminais de galactosil dos galactosídeos. Muitos estudos têm mostrado que esta enzima catalisa a hidrólise de resíduos de galactosil de carboidratos, glicoproteínas e galactolipídios (ESTEBAN et al., 2005).

A atividade da $\beta$-Galactosidase ( $\beta$-Gal) está diretamente relacionada com a perda de firmeza em mamão cv. Eksotika, sendo mais intensa na região externa do tecido do mesocarpo. Segundo Lazan et al. (1995), o incremento na atividade, durante o amadurecimento, é proporcional à redução de firmeza da polpa. Um aumento na atividade de $249 \%$ para frutos desta mesma variedade, entre os estádios pré-climatérico e maduro, foi relatado por Ali et al. (2004). No caso de mamões cv. Solo armazenados a $22{ }^{\circ} \mathrm{C}$, D'innocenzo e Lajolo (2001) identificaram um expressivo aumento da atividade da $\beta$-Gal até 8 dias de armazenamento, período no qual ocorreu a redução total de firmeza do tecido.

Neste trabalho, foi investigada a relação entre as atividades das enzimas pectina metilesterase (PME) e $\beta$-galactosidase ( $\beta$-Gal) e o amadurecimento de frutos de mamoeiro (Carica papaya L.) cv. Golden.

\section{MATERIAL E MÉTODOS}

\section{Matéria-prima e preparo das amostras.}

Frutos de mamoeiro cv. Golden, apresentando aproximadamente $15 \%$ de cor amarela na casca (na extremidade basal) e peso médio de $500 \mathrm{~g}$, foram selecionados na linha de embalagem da Caliman Agrícola S.A. (Linhares-ES), em fevereiro de 2007. Os frutos, após passarem por tratamento hidrotérmico $\left(48^{\circ} \mathrm{C} / 20 \mathrm{~min}\right.$ ) e banho com fungicida ( $2 \mathrm{~min}$ ), foram transportados sob refrigeração até o laboratório, 
onde os experimentos foram realizados $24 \mathrm{~h}$ após a colheita.

Sessenta e seis frutos foram estocados em câmara de refrigeração a $20^{\circ} \mathrm{C}$ e umidade relativa de 85 a $95 \%$ por um período de 11 dias. Em intervalos de tempo de um dia, foram retirados 6 frutos para a determinação da cor da casca, firmeza da polpa, $\mathrm{pH}$ e atividade da PME e $\beta$-Gal. Os frutos foram divididos transversalmente na região equatorial $\mathrm{e}$, posteriormente, foi realizado um corte longitudinal, separando o lado de fruto que ficou exposto à radiação solar (lado exposto ao sol) durante o período após a antese. As extremidades foram descartadas. A fim de homogeneizar as medidas, as análises foram feitas somente na parte do fruto exposta ao sol.

A coloração da casca e a firmeza da polpa foram determinadas imediatamente após a retirada dos mamões da câmara. Para a determinação do $\mathrm{pH}$ e a realização do ensaio enzimático, amostras da região externa do mesocarpo dos frutos foram removidas, pesadas, embaladas em papel-alumínio e imediatamente congeladas em nitrogênio líquido. Em seguida, foram estocadas em ultrafreezer a $-70^{\circ}$ C até o seu uso.

\section{Firmeza da polpa}

As medidas de firmeza da polpa foram realizadas com auxílio de um penetrômetro digital de bancada (Turoni, modelo 53205) com sonda de $8 \mathrm{~mm}$ de diâmetro. Os frutos foram partidos transversalmente na região equatorial, e as medidas, realizadas em dois pontos equidistantes na metade externa (próxima da casca), na região do fruto exposta ao sol. Os resultados representam a força em Newton necessária para penetrar $11 \mathrm{~mm}$ na polpa.

\section{Coloração da casca}

A coloração da casca dos frutos foi determinada utilizando um colorímetro de Hunter (Hunterlab MiniScan XE Plus, USA), calibrado com padrões de placas preta e branca. Utilizou-se o padrão de iluminação D65 com ângulo de $10^{\circ}$. Realizaram-se quatro leituras em pontos equidistantes da região equatorial do fruto. Os resultados foram caracterizados pelas medidas do ângulo hue (hue $\left.{ }^{0}\right)$. A evolução do amadurecimento foi avaliada pelos valores de ângulo hue entre $120^{\circ}$ e $60^{\circ}$, que indicam a mudança da cor verde para a amarela da casca.

\section{Determinação do $\mathbf{p H}$}

As determinações do $\mathrm{pH}$ da polpa dos frutos foram realizadas em solução de aproximadamente $5 \mathrm{~g}$ da polpa homogeneizada (Tecnal, Turratec TE 102) a $25.000 \mathrm{rpm}$, por dois minutos, e transferida para um erlenmeyer de $250 \mathrm{~mL}$, com o volume completado para $150 \mathrm{~mL}$ com água destilada. $\mathrm{O} \mathrm{pH}$ foi medido usando um medidor de $\mathrm{pH}$ (WTW, modelo 330 SET1), calibrado com soluções-padrão de pH 4,0 e 7,0.

\section{Determinação da atividade da pectina metilesterase (PME)}

Para a extração da PME, $5 \mathrm{~g}$ de polpa de mamão foram homogeneizadas (Tecnal, Turratec TE102) em $40 \mathrm{~mL}$ de uma solução de $\mathrm{NaCl}$ 1,0 M, pH 7,5, contendo $1,0 \%(\mathrm{p} / \mathrm{v})$ de polivinilpolipirrolidona (PVPP) insolúvel. Esta solução foi centrifugada a $15.000 \mathrm{~g}$, durante 30 minutos, em centrífuga refrigerada a $-4^{\circ} \mathrm{C}$, e o sobrenadante (extrato enzimático), utilizado para a dosagem da atividade da enzima.

O método utilizado para a determinação da atividade da PME foi baseado na troca de cor de um indicador de $\mathrm{pH}$ apropriado, durante a realização de catálise da enzima. Na medida em que as ligações ésteres da pectina foram hidrolisadas, grupos ácidos foram produzidos, provocando uma redução no $\mathrm{pH}$ e, como consequência, ocorreu uma alteração na cor do indicador (HAGERMAN; AUSTIN, 1986). Esta mudança de cor foi monitorada de forma contínua em um espectrofotômetro Hitachi modelo U 2000.

Como substrato, foi utilizada uma mistura de pectina de cítrus (Sigma, p.a.) e azul de bromotimol (3,3-dibromotimosulfenolftaleina), pKa 6,0. A pectina $(0,5 \%, \mathrm{p} / \mathrm{v})$ foi solubilizada em água destilada aquecida a $80{ }^{\circ} \mathrm{C}$ sob agitação constante e, posteriormente, mantida em repouso até alcançar a temperatura ambiente, sendo então ajustado o $\mathrm{pH}$ para 7,5. A solução de azul de bromotimol 0,01 $\%(\mathrm{p} / \mathrm{v})$ foi preparada diluindo-se essa substância em tampão fosfato de potássio 3,0 mM, pH 7,5. O substrato foi então preparado, misturando-se $75 \mu \mathrm{L}$ de azul de bromotimol para cada $1,0 \mathrm{~mL}$ da pectina.

$\mathrm{Na}$ determinação da atividade da PME, 0,8 $\mathrm{mL}$ do extrato enzimático, corrigido para $\mathrm{pH} 7,5$, foi adicionado a $2,0 \mathrm{~mL}$ da solução de pectina contendo o azul de bromotimol e $0,2 \mathrm{~mL}$ de $\mathrm{NaCl} 1 \mathrm{M}$. Esta solução foi incubada a $80^{\circ} \mathrm{C}$, e o decréscimo da absorbância a $620 \mathrm{~nm}$, monitorada por 1 minuto, com leituras em intervalos de 10 segundos. As medidas foram convertidas para $\mu$ mol de ácido produzido por minuto, através de uma curva de calibração, utilizando o ácido galacturônico como padrão. Uma unidade da PME foi definida como a quantidade de enzima que libera $1 \mu \mathrm{mol}$ de ácido galacturônico por minuto, a $80^{\circ} \mathrm{C}$. A concentração de proteínas foi determinada conforme o método descrito por 
Bradford (1976)

\section{Determinação da atividade da $\beta$-galactosidase ( $\beta$-Gal)}

Para a extração da $\beta$-Gal, amostras do mesocarpo externo do mamão foram homogeneizadas (Tecnal, Turratec TE-102) em solução gelada de tampão acetato de sódio $50 \mathrm{mM}, \mathrm{pH} 5,0$, contendo $1 \mathrm{M}$ de $\mathrm{NaCl}$ e $10 \%$ de PVPP, durante 6 minutos, a $4^{\circ} \mathrm{C}$, na proporção de $1: 3$. Após 2 horas de repouso a $4^{\circ} \mathrm{C}$, a solução foi filtrada em 2 camadas de tecido de algodão, e o filtrado, centrifugado (centrífuga HERMLE Z $382 \mathrm{~K}$ ) a $12.000 \mathrm{~g}$ por 20 minutos, a $4^{\circ} \mathrm{C}$ (VICENTE et al., 2005).

A atividade da $\beta$-Gal foi determinada incubando-se $1,5 \mathrm{~mL}$ de tampão acetato de sódio a $50 \mathrm{mM}, \mathrm{pH} 4,5$, contendo $3 \mathrm{mM}$ de p-nitrofenil -D-galactopiranosídeo com $0,5 \mathrm{~mL}$ do extrato enzimático, a $55^{\circ} \mathrm{C}$, durante 20 minutos. Posteriormente, alíquotas de $0,15 \mathrm{~mL}$ foram retiradas e adicionadas a $1,0 \mathrm{~mL}$ de solução de $\mathrm{Na}_{2} \mathrm{CO}_{3} 0,4 \mathrm{M}$, a fim de paralisar a reação. A coloração desenvolvida foi medida através de espectrofotômetro Hitachi modelo U 2000. Uma unidade da $\beta$-Gal foi definida como a quantidade de enzima necessária para produzir 1 $\mu \mathrm{mol}$ de $p$-nitrofenol por minuto, por mL. Os níveis da atividade enzimática foram expressos em unidade por volume $(\mathrm{U} / \mathrm{mL})$.

\section{Delineamento experimental e análise estatística}

Os frutos foram selecionados segundo o método de amostragem simples ao acaso, e as amostras foram dimensionadas considerando o desvio de $10 \%$ em torno da média da amostra de 66 frutos e $\alpha=5 \%$ de probabilidade. Após o dimensionamento da amostra, foram obtidos os intervalos de confiança a 95\% de probabilidade, para a média das medidas para a população em estudo e, posteriormente, foram obtidas as equações de regressão, considerando o modelo linear polinomial. Em todos os testes realizados, as conclusões foram estabelecidas ao nível de $5 \%$ de probabilidade.

\section{RESULTADOS E DISCUSSÃO}

O tamanho mínimo de amostras de uma população infinita de mamões Golden e o intervalo de confiança para as medidas de atividade das enzimas $\beta$-Gal e PME e para as análises de firmeza, $\mathrm{pH}$ e cor da casca, utilizando um nível de $5 \%$ de probabilidade e considerando uma amostragem simples ao acaso, estão apresentados na Tabela 1. A análise de regressão dos dados dos diferentes parâmetros ava- liados neste trabalho contemplou uma amostragem de população infinita, pois, com exceção das medidas de firmeza de polpa, o tamanho mínimo de amostragem foi menor do que a amostragem de 66 frutos.

A mudança da cor da casca dos frutos, durante o armazenamento por 11 dias, a $85-95 \%$ UR, foi caracterizada pelas medidas do ângulo hue (Figura 1). Durante este período, os frutos mudaram da coloração verde-clara, com valores de aproximadamente 100 ohue, para a cor amarelada, com 68 'hue. Resultados similares foram encontrados por Hernández et al. (2006), que também observaram uma redução nos valores do ângulo hue durante o amadurecimento do mamão-'Baixinho-de-Santa-Amália'.

Após quatro dias de armazenamento, os frutos apresentaram valores do ângulo hue menores do que 80 , indicando a perda expressiva da cor verde da casca. Neste mesmo período, foram observados os mais baixos valores de $\mathrm{pH}$ (Figura 2). A perda da cor verde resulta da quebra da estrutura de clorofila, causada principalmente pelas mudanças de $\mathrm{pH}$, resultantes da presença de ácidos orgânicos provenientes do vacúolo, pela presença de sistemas oxidantes e pela atividade de clorofilases (EC 3.1.1.14) (AWAD, 1993).

Inicialmente, houve decréscimo nos valores de $\mathrm{pH}$ até o quarto dia de armazenamento, causado, provavelmente, por aumento na concentração de ácidos orgânicos resultantes da degradação da parede celular pelas enzimas pécticas.

Segundo Draetta et al. (1975), o aumento na acidez na polpa dos frutos de mamoeiro, ao longo do seu amadurecimento, está vinculado à formação de ácido galacturônico proveniente da hidrólise da pectina pela enzima pectina metilesterase. A partir do quinto dia de armazenamento, ocorreu aumento nos valores de $\mathrm{pH}$, indicando que houve utilização dos ácidos orgânicos que constituem uma excelente reserva energética para sustentar o amadurecimento do fruto (CHITARRA; CHITARRA, 2005). No estudo de armazenamento de mamões 'Golden ' mantidos em condições de refrigeração, Almeida et al. (2006) e Pinto et al. (2006) também identificaram uma significativa flutuação de acidez durante a estocagem dos frutos, sendo que estas transformações foram retardadas por baixas temperaturas.

A variação da atividade da $\mathrm{PME}$, durante o armazenamento do mamão cv. Golden por 11 dias, a $20^{\circ} \mathrm{C}$ e $85-95 \%$ UR, está mostrada na Figura 3. Alta atividade da enzima foi encontrada no início do armazenamento, que decresceu drasticamente até o terceiro dia, coincidindo com a fase inicial de amadurecimento do fruto, quando ocorreu expressiva redução de $\mathrm{pH}$ (Figura 2). Posteriormente, a atividade desta enzima 
apresentou um pequeno aumento, ocorrendo flutuações na fase intermediária, com valores máximos no quinto dia de armazenamento. Resultados similares foram encontrados por Fontes et al. (2008), em que a atividade da PME em mamões cv. Sunrise Solo foi alta no primeiro dia após a colheita e reduziuse gradativamente até o $4^{\circ}$ dia, quando atingiu seu menor valor. No quinto dia, a atividade aumentou, permanecendo praticamente inalterada até o oitavo dia após a colheita.

Por outro lado, o comportamento da PME observado neste trabalho foi diferente do observado por Lazan et al. (1995), para mamões da cv. Eksotika, em que a atividade da PME aumentou gradativamente durante o amadurecimento do fruto. Os relatos na literatura sobre a atividade da PME durante o amadurecimento dos frutos são controversos. A atividade da PME pode diminuir, permanecer constante ou aumentar durante a maturação, dependendo do fruto e do método de extração da enzima. As mudanças são complicadas, ainda, pela presença de isoformas ou inibidores enzimáticos (ALI et al., 2004).

A importância da PME no amaciamento dos frutos é ampliada quando se considera que esta enzima pode ajudar direta ou indiretamente a ação de outras, ao criar um ambiente iônico adequado ou, possivelmente, ao modificar a porosidade da parede celular. Desta forma, ela favorece o acesso de outras enzimas aos seus substratos potenciais (ALI et al., 2004). Para o mamão cv. Golden, Silva et al. (2006) verificaram que a enzima poligalacturonase apresenta uma intensa atividade no início do amadurecimento dos frutos e contribui com o amaciamento da polpa. Desta forma, a expressiva atividade inicial da PME disponibilizaria substrato para a atuação da poligalacturonase.

As mudanças na atividade da $\beta$-Gal, durante o amadurecimento dos mamões, foram proporcionalmente inversas àquelas observadas para a PME (Figura 4).

A enzima $\beta$-Gal dobrou a sua atividade nos dois primeiros dias de armazenamento dos frutos, sendo que, posteriormente, apresentou flutuações com pequeno aumento da atividade até o final do armazenamento. No entanto, ocorreu um pequeno declínio na atividade desta enzima no quarto e no décimo dia de armazenamento, períodos em que foram encontradas as maiores atividades relativas da enzima PME. Nota-se que, durante o armazenamento do mamão cv. Golden, o período de máxima atividade da PME (Figura 3) precede aquele de máxima atividade da $\beta$-Gal (Figura 4).

Vários autores também observaram um aumento na atividade da $\beta$-Gal durante o amadureci- mento do mamão (TATEISHI et al., 2007; MWANIKI et al., 2005; LAZAN et al., 2004; KARAKURT; HUBER, 2003; ALI et al., 2004). Segundo Soh et al. (2006), a enzima $\alpha$-Gal aumentou em até seis vezes a sua atividade durante o amadurecimento do mamão.

Em relação à firmeza da polpa dos frutos, foi observada uma redução drástica nos dois primeiros dias de armazenamento (Figura 5). Este amaciamento intenso no início do amadurecimento foi constatado também por Almeida et al. (2005). Neste período, também foram observados decréscimo na atividade da PME e aumento na atividade da $\beta$-Gal. Isto indica que, em um primeiro momento, a PME atua de modo mais efetivo no amadurecimento do mamão. Entretanto, a queda precoce de sua atividade indica que a $\beta$-Gal tem um papel fundamental na rápida perda de firmeza do mamão cv. Golden. A correlação direta entre a redução da firmeza e o aumento da atividade da $\beta$-Gal foi relatada também por Lazan et al. (1995) para o mamão cv. Eksotika e por D'innocenzo e Lajolo (2001) para mamões cv. Solo.

Segundo Gallego e Zarra (1998), a solubilização de pectinas e a liberação de resíduos galactosil das galactanas, associadas à celulose, poderiam explicar parcialmente o amaciamento. Em razão da complexidade da estrutura da parede celular, é improvável que uma enzima, em particular, seja capaz de modificá-la significativamente e responder pelo amaciamento (ALI et al., 2004). Ações coletivas e sinergística de várias enzimas seriam necessárias para promover mudanças texturais relevantes (GIOVANNONI, 2001; MWANIKI et al., 2005). 
TABELA 1 - Tamanho mínimo de amostragem e intervalos de confiança para a média das medidas de $\beta$-Gal e PME, firmeza de polpa, $\mathrm{pH}$ e cor da casca de mamões cv. Golden armazenados a $20^{\circ} \mathrm{C}$, durante 11 dias, considerando $95 \%$ de probabilidade de ocorrência em uma população infinita de frutos.

\begin{tabular}{lcc}
\hline Parâmetros & $\begin{array}{c}\text { Valores médios } \\
\text { (com intervalos de confiança) }\end{array}$ & $\begin{array}{c}\text { Tamanho de amostragem } \\
\text { (número de frutos) }\end{array}$ \\
\hline PME & $163,29 \pm 10,47$ & 27 \\
$\beta$-Gal & $2,04 \pm 0,12$ & 18 \\
Firmeza & $5,97 \pm 1,37$ & 346 \\
pH & $5,52 \pm 0,03$ & 1 \\
Ângulo hue & $75,75 \pm 2,14$ & 5 \\
\hline
\end{tabular}

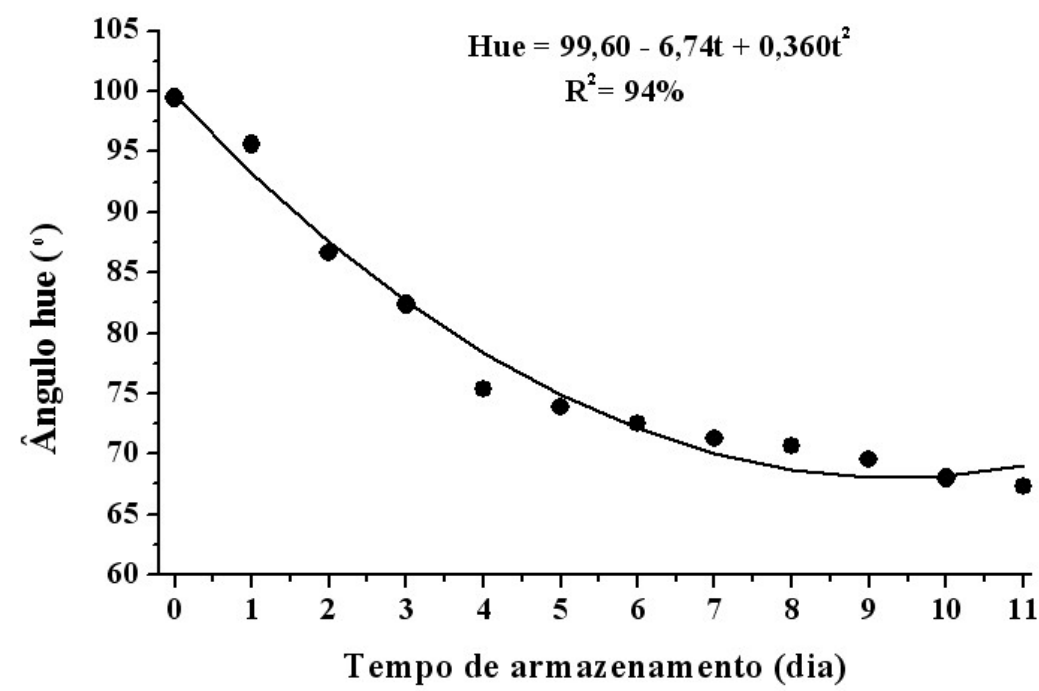

FIGURA 1 - Variação na cor da casca de mamões cv. Golden armazenados por 11 dias, a $20^{\circ} \mathrm{C}$ e $85-95 \%$ UR.

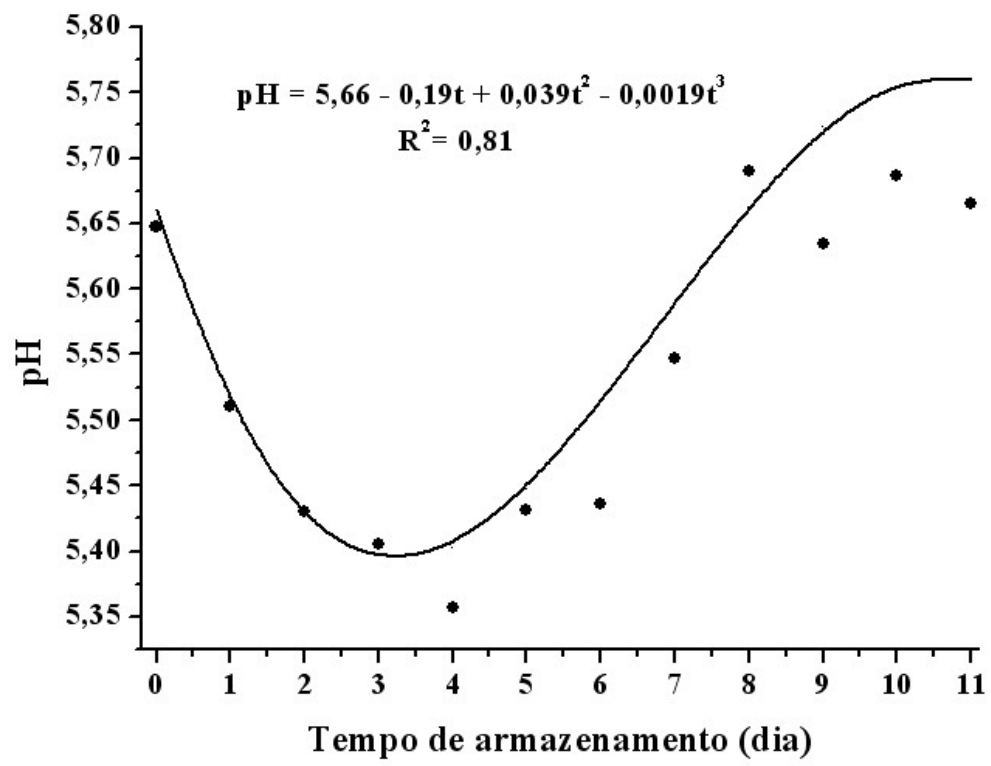

FIGURA 2 - Variação no pH da polpa de mamões cv. Golden armazenados por 11 dias, a $20{ }^{\circ} \mathrm{C}$ e $85-95 \%$ UR. 


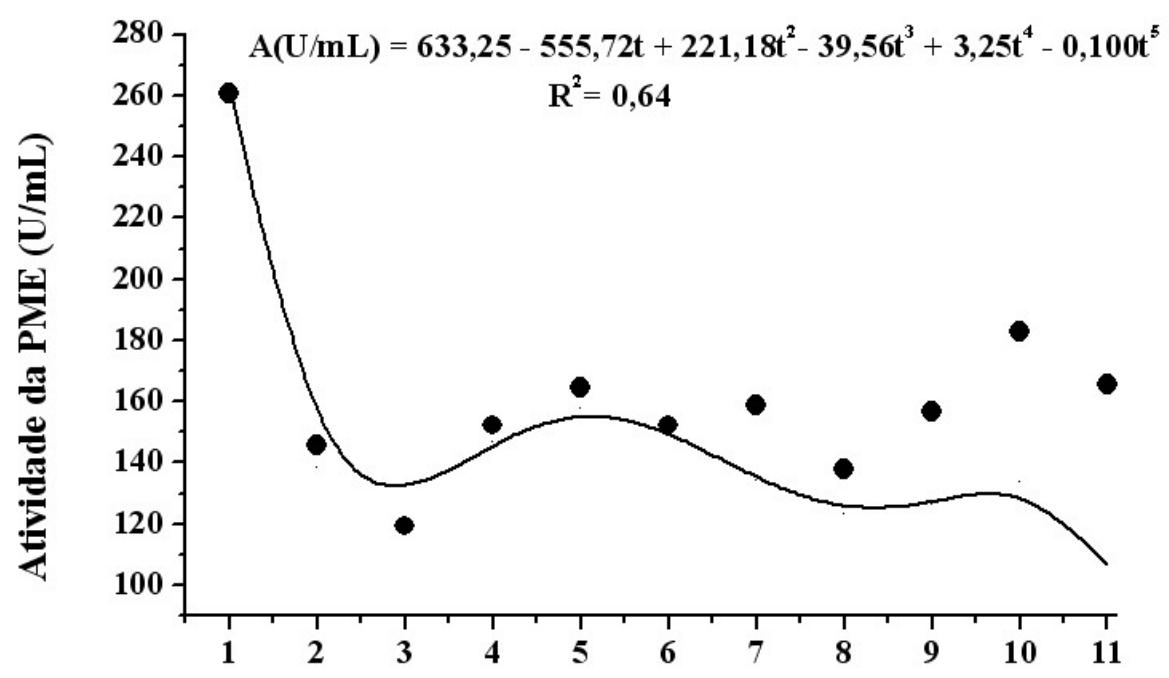

FIGURA 3 - Atividade da PME na polpa de mamões cv. Golden armazenàdos por 11 dias, a $20^{\circ} \mathrm{C}$ e $85-95$ $\%$ UR.

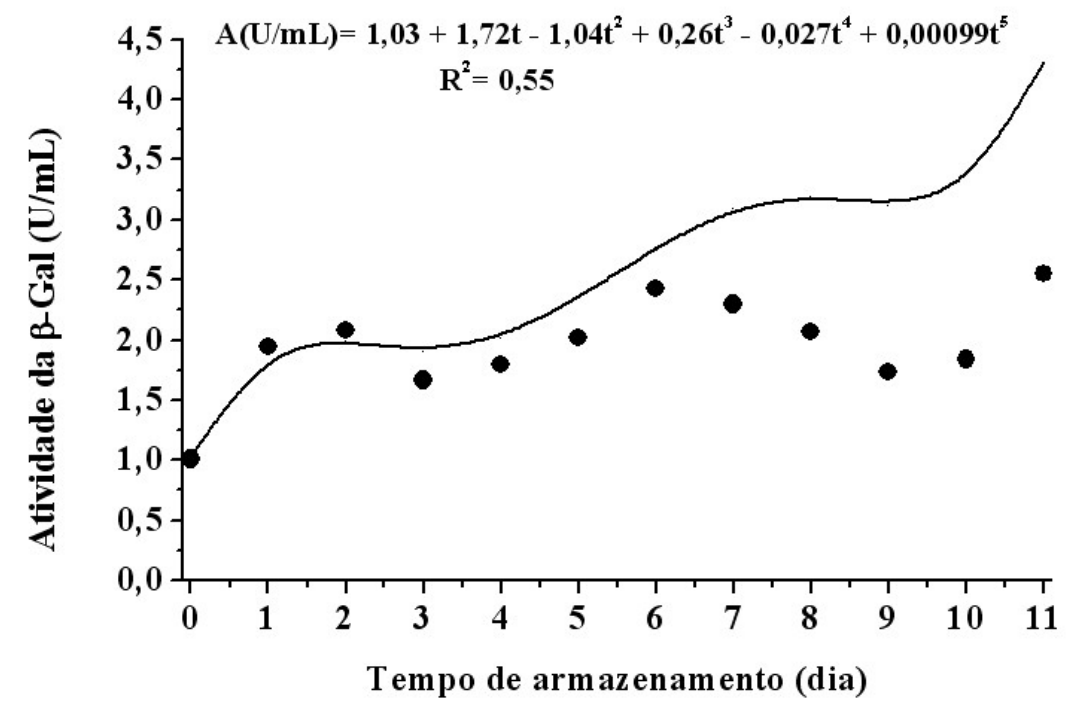

FIGURA 4 - Atividade da $\beta$-Gal na polpa de mamões cv. Golden armazenados por 11 dias, a $20^{\circ} \mathrm{C}$ e $85-95$ $\%$ UR. 


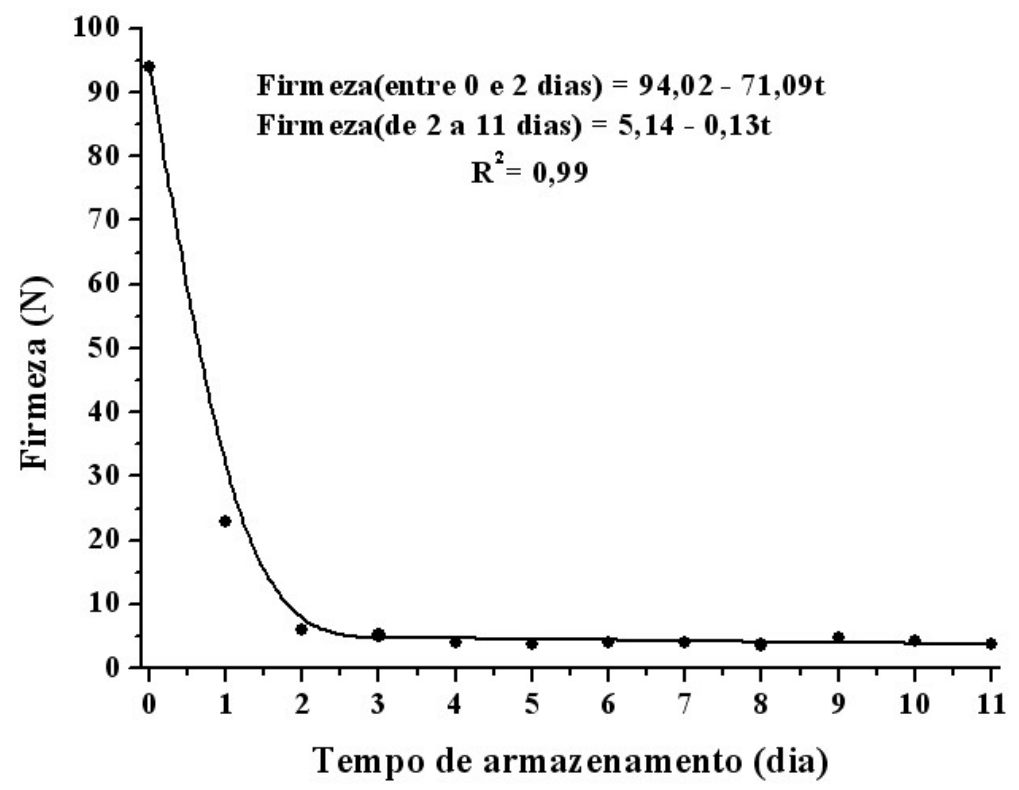

FIGURA 5 - Variação na firmeza da polpa de mamões cv. Golden armazenados por 11 dias, a $20^{\circ} \mathrm{C}$ e 85 $90 \%$ UR.

\section{CONCLUSÕES}

Diante dos resultados encontrados neste trabalho, conclui-se que ambas as enzimas investigadas, PME e $\beta$-Gal, são responsáveis pela despolimerização das substâncias pécticas e consequente amaciamento da polpa do mamão cv. Golden durante o amadurecimento. A PME é mais efetiva no início do amadurecimento, e a $\beta$-Gal apresenta aumento abrupto no início, com maior atividade nos períodos intermediário e final do amadurecimento. Verifica-se que, durante o amadurecimento, ocorrem flutuações na intensidade de atividade destas enzimas, sendo que períodos de maior intensidade da PME precedem os períodos de maior atividade da $\beta$-Gal.

\section{AGRADECIMENTOS}

Os autores agradecem à FINEP, CNPq e à FAPERJ, pelo financiamento da pesquisa, e à CALIMAN AGRÍCOLA S.A., pela parceria no projeto FRUTIMAMÃO.

\section{REFERÊNCIAS}

ALI, Z.M.; CHIN, L.H.; LAZAN, H. A comparative study on wall degrading enzymes, pectin modifications and softening during ripening of selected tropical fruits. Plant Science, Limerick, v.167, p.317-327, 2004.

ALMEIDA, R.F.; RESENDE, E.D.; VITORAZI, L.; CARLOS, L.A.; PINTO, L.K.A.; SILVA, H.R.F.; MARTINS, M.L.L. Injúria pelo frio em frutos de mamoeiro (Carica papaya L.) cv.'Golden`. Revista Brasileira de Fruticultura, Jaboticabal, v.27, n.1, p.17-20, 2005.

ALMEIDA, R.F.; MARTINS, M.L.L.; RESENDE, E.D.; VITORAZI, L.; CARLOS, L.A.; PINTO, L.K.A. Influence of the refrigerating temperature on the chemical characteristics of papaya fruits $\mathrm{cv}$. Golden. Ciência e Tecnologia de Alimentos, Campinas, v.26, n.3, p.577-581, 2006.

ARBAISAH, S.M.; SABIH, B.A.; JUNAINAH, A.H.; JAMILAH, B. Determination of optimum conditions for pectinase extraction from soursop fruit (Anona muricata) using response surface methodology. Food Chemistry, London, v. 55, n. 3, p. 289-292, 1996. 
ASIF, M.H.; NATH, P. Expression of multiple forms of polygalacturonase gene during ripening in banana fruit. Plant Physiology and Biochemistry, Paris, v. 43, n. 2, 177-184, 2005.

AWAD, M. Fisiologia pós-colheita de frutos. São Paulo: Nobel, 1993. 114p.

BICALHO, U.O.; CHITARRA, A.B.; CHITARRA, M.I.F.; COELHO, A.H. Modificações texturais em mamões submetidos à aplicação pós-colheita de cálcio e embalagens de PVC. Ciência e Agrotecnologia, Lavras, v. 24, n. 1, p. 136-146, 2000.

BRADFORD, M.M. A rapid and sensitive method for the quantitation of microgram quantities of protein utilizing the principle of protein-dye binding. Analytical Biochemistry, New York, v. 72, p. 248254, 1976.

BRUMMEL, D.A.; LABAVITCH, J.M. Effect of antisense suppression of endopolygalacturonase activity on polyuronide molecular weight in ripening tomato fruit and in fruit homogenates. Plant Physiology, Minneapolis, v. 115, p. 717-725, 1997.

CHITARRA, M.I.F.; CHITARRA, A.B. Pós-colheita de frutas e hortaliças: fisiologia e manuseio. 2. ed. Lavras: UFLA, 2005. 785p.

D'INNOCENZO, M.; LAJOLO, F.M. Effect of gamma irradiation on softening changes and enzyme activities during ripening of papaya fruit. Journal Food Biochemistry, Westport, v.25, p.425-438, 2001.

DRAETTA, I.S.; SHIMOKAMI, M.; YOKOMIZO, Y.; FUJITA, J.T.; MENEZES, H.C.; BLEINORITH, E.W. Transformações bioquímicas do mamão (Carica papaya L.) durante a maturação. Coletânea do Instituto de Tecnologia de Alimentos, Campinas, v. 6, n.1, p. 395-408, 1975.

ESTEBAN R.; LABRADOR, E.; DOPICO B. A family of beta-galactosidase cDNAs related to development of vegetative tissue in Cicer arietinun. Plant Science, Limerick, v. 168, n. 2, p. 457-466, 2005.

FONTES, R.V.; SANTOS, M.P.; FALQUETO, A.R.; SILVA, D.M. Atividade da pectinametilesterase e sua relação com a perda de firmeza da polpa de mamão cv. Sunrise Solo e Tainung. Revista Brasileira de Fruticultura, Jaboticabal, v.30, n.1, p. 54-58, 2008.
GALLEGO, P.P.; ZARRA, I. Cell wall autolysis during kiwifruit development. Annals of Botany, London, v.81, n.1, p.91-96, 1998.

GIOVANNONI, J. Molecular biology of fruit maturation and ripening. Annual Review of Plant Physiology and Plant Molecular Biology, Palo Alto, v. 52, p.725-749, 2001.

HAGERMAN, A.E.; AUSTIN, P.J. Continuous spectrophotometric assay for plant pectin methyl esterase. Journal Agricultural Food Chemistry, Easton, v.34, p. 440-444, 1986.

HERNÁNDEZ, Y.; LOBO, M.G.; GONZÁLEZ, M. Determination of vitamin $\mathrm{C}$ in tropical fruits: A comparative evaluation of methods. Food Chemistry, London, v 96, n.7, 654-664, 2006.

HUBER, D.J. Polyuronide degradation and hemicellulose modifications in ripening tomato fruit. Journal of the American Society of Horticultural Science, Alexandria, v. 108, p. 405-409, 1983.

JACOMINO, A.P.; KLUGE, R.A.; BRACKMANN, A.; CASTRO, P.R.C. Amadurecimento e senescência de mamão com 1-metilciclopropeno. Scientia Agricola, Piracicaba, v. 59, n. 2, p. 303-308, 2002.

KARAKURT, Y.; HUBER, D.J. Activities of several membrane and cell-wall hydrolases, ethylene biosynthetic enzymes, and cell wall polyuronide degradation during low-temperature storage of intact and fresh-cut papaya (Carica papaya) fruit. Postharvest Biology and Technology, Amsterdam, v.28, n.2, p.219-229, 2003.

LAZAN, H.; Ng, S.Y.; GOH, L.Y.; ALI, Z.M. Papaya $\beta$-galactosidase/galactanase isoforms in differential cell wall hydrolysis and fruit softening during ripening. Plant Physiology and Biochemistry, Copenhagem, v.42, n.7, 847-853, 2004.

LAZAN, H.; SELAMAT, M.K.; ALI, Z.M. $\beta$-Galactosidase, polygalacturonase and pectinesterase in differential softening and cell wall modification during papaya fruit ripening. Physiologia Plantarum, Copenhagem, v. 95, p. 106-112, 1995. 
MWANIKI, M.W.; MATHOOKO, F.M.; MAATSUZAKI, M.; HIWASA, K.; TATEISHI, A.; USHIJIMA, K.; NAKANO, R.; INABA, A.; KUBO, Y. Expression characteristics of seven members of the b-galactosidase gene family in 'La France' pear (Pyrus communis L.) fruit during growth and their regulation by 1 -methylcyclopropene during postharvest ripening. Postharvest Biology and Technology, New Dehli, v. 36, p. 253-263, 2005.

PAULL, R.E., CHEN, N.J. Postharvest variation in cell wall-degradation enzymes of papaya (Carica papaya L.) during ripening. Plant Physiology, Washington, v. 72, p. 382-385, 1983.

PINTO, L.K.A.; MARTINS, M.L.L.; RESENDE, E.D.; ALMEIDA, R.F.; VITORAZI, L.; PEREIRA, S.M.F. Influence of the modified atmosphere by plastic films on the quality of papaya fruit stored under refrigeration. Ciência e Tecnologia de Alimentos, Campinas, v.26, n.4, p.444-451, 2006.

SILVA, H.R.F.; RESENDE, E.D.; PINTO, L.K.A.; ALMEIDA, R.F.; MARTINS, M.L.L. Atividade da enzima poligalacturonase em frutos de mamoeiro cv. Golden armazenados sob refrigeração. Revista Brasileira de Armazenamento, Viçosa, MG, v.31, p. 187-191, 2006.
SOH, C.P.; ALI, Z.M.; LAZAN, H. Characterization of an alfa-galactosidase with potential relevance to ripening related texture changes. Phytochemistry, Oxford, v. 67, p. 242-254, 2006.

SOZZI, G., CASCONE, O., FRASCHINA, A.A. Effect of high-temperature stress on endo- $\beta$-mannase $\alpha$-and- $\beta$ galactosidase activities during tomato fruit ripening. Postharvest Biology and Technology, Amsterdam, v. 9, p. 54-63, 1996.

TATEISHI, A.; SHIBA, H.; OGIHARA, J.; ISOBE, K.; NOMURA, K.; WATANABE, K.; INOUE, H. Differential expression and ethylene regulation of beta-galactosidase genes and isozymes isolated from avocado (Persea americana Mill.) fruit. Postharvest Biology and Technology, Amsterdam, v.45, n.1, 56-65, 2007.

VICENTE, A.R.; COSTA, M.L.; MARTINEZ, G.A.; CHAVES, A.R.; CIVELLO, P.M. Effect of heat treatment on cell wall degradation and softening in strawberry fruit. Postharvest Biology and Technology, Amsterdam, v. 38, p. 213-222, 2005. 